\title{
cmaJOPEN
}

\section{Cost-effectiveness of antithrombotic agents for atrial fibrillation in older adults at risk for falls: a mathematical modelling study}

\author{
Eric K.C. Wong MD, Christina Belza MN, David M.J. Naimark MD MSc, Sharon E. Straus MD MSc, \\ Harindra C. Wijeysundera MD PhD
}

Abstract

Background: Antithrombotic drugs decrease stroke risk in patients with atrial fibrillation, but they increase bleeding risk, particularly in older adults at high risk for falls. We aimed to determine the most cost-effective antithrombotic therapy in older adults with atrial fibrillation who are at high risk for falls.

\begin{abstract}
Methods: We conducted a mathematical modelling study from July 2019 to March 2020 based on the Ontario, Canada, health care system. We derived the base-case age, sex and fall risk distribution from a published cohort of older adults at risk for falls, and the bleeding and stroke risk parameters from an atrial fibrillation trial population. Using a probabilistic microsimulation Markov decision model, we calculated quality-adjusted life years (QALYs), total cost and incremental cost-effectiveness ratios (ICERs) for each of acetylsalicylic acid (ASA), warfarin, apixaban, dabigatran, rivaroxaban and edoxaban. Cost data were adjusted for inflation to 2018 values. The analysis used the Ontario public payer perspective with a lifetime horizon.
\end{abstract}

Results: In our model, the most cost-effective antithrombotic therapy for atrial fibrillation in older patients at risk for falls was apixaban, with an ICER of $\$ 8517$ per QALY gained (5.86 QALYs at \$92 056) over ASA. It was a dominant strategy over warfarin and the other antithrombotic agents. There was moderate uncertainty in cost-effectiveness ranking, with apixaban as the preferred choice in $66 \%$ of model iterations (given willingness to pay of $\$ 50000$ per QALY gained); edoxaban, $30 \mathrm{mg}$, was preferred in $31 \%$ of iterations. Sensitivity analysis across ranges of age, bleeding risk and fall risk still favoured apixaban over the other medications.

Interpretation: From a public payer perspective, apixaban is the most cost-effective antithrombotic agent in older adults at high risk for falls. Health care funders should implement strategies to encourage use of the most cost-effective medication in this population.

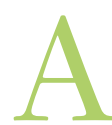

trial fibrillation is a common type of dysrhythmia. It increases stroke risk owing to abnormal atrial tissue substrate and stasis from contractile dysfunction. ${ }^{1}$ Antithrombotic therapies are used to prevent stroke in patients with atrial fibrillation, but these medications increase bleeding risk. ${ }^{2}$ The prevalence of atrial fibrillation, ${ }^{3}$ stroke risk ${ }^{4}$ and bleeding risk ${ }^{5}$ all increase with increasing age. Furthermore, older adults are often at increased risk of falling and head injury, which can lead to serious bleeding with antithrombotic therapy. ${ }^{6}$ The fear of causing major bleeding leads to underprescribing of antithrombotics in older patients, particularly those at high risk of falling. ${ }^{7}$

A decision analysis study published in 1999 showed that warfarin was preferred (12.90 quality-adjusted life years [QALYs]) over acetylsalicylic acid (ASA) (11.17 QALYs) or no treatment (10.15 QALYs) for atrial fibrillation in those at risk for falls. ${ }^{8}$ More recently, direct oral anticoagulants, including dabigatran, rivaroxaban, apixaban and edoxaban, offer generally lower bleeding risk than warfarin, with similar or higher stroke-prevention effectiveness. ${ }^{9}$ Direct oral anticoagulants are economically attractive compared to warfarin in the general Canadian population, ${ }^{10}$ but whether this holds for an older population with falls is uncertain. Older adults with atrial fibrillation and falls have both higher stroke risk and higher bleeding risk, so the balance between risk and efficacy of direct oral anticoagulants needs to be reflected in economic evaluations.

We developed such a model to compare warfarin, ASA and the 4 direct oral anticoagulants for their cost-effectiveness in older adults with atrial fibrillation who are at high risk for falls using the public health care payer perspective in Ontario, Canada.

Competing interests: None declared.

This article has been peer reviewed.

Correspondence to: Eric Wong, eric.wong@medportal.ca

CMAJ Open 2020. DOI:10.9778/cmajo.20200107 


\section{Methods}

\section{Study design}

We conducted a mathematical modelling study from July 2019 to March 2020. Decision models can be used to determine optimal treatment choices for a population where direct evidence is limited or not available. They can incorporate event probabilities, trade-offs, patient preferences and treatment costs to compare consequences, in terms of lifetime costs and quality-adjusted life expectancy, of treatment choices for a population. ${ }^{11}$

\section{Model structure}

We constructed a discrete-time, health state transition (Markov) model employing 2-dimensional Monte Carlo simulation in TreeAge Pro 2020 (TreeAge Software) to compare the different antithrombotic agents for older patients with nonvalvular atrial fibrillation. Details of the model structure are given in Appendix 1 (available at www.cmajopen.ca/content/8/4/E706/ suppl/DC1).

Two-dimensional simulation refers to simulating the variability of patient characteristics and model parameters, such as event probabilities, separately. Patient characteristics and model parameters are generated randomly from specified distributions based on literature estimates. The computer draws a set of model parameters in an outer loop first, followed by the generation of individual simulated patients with unique characteristics (age, sex, stroke risk according to the CHADS [congestive heart failure, hypertension, age $\geq 75 \mathrm{yr}$, diabetes, stroke] score, ${ }^{12}$ bleeding risk according to the HAS-BLED [hypertension, abnormal renal and liver function, stroke, bleeding, labile international normalized ratio, elderly (age $>65 \mathrm{yr}$ ), drugs or alcohol ( $\geq 8$ drinks/wk)] score ${ }^{13}$ and fall risk) in an inner loop. The process is iterated to produce outcomes with increased precision (hence "loops"). Sampling individual patient characteristics allows both for a representation of individual variability and for the probabilities of transition among various health states to depend on a given patient's attributes. We ran each hypothetical patient through each of the antithrombotic strategies in turn.

We derived the base-case age, sex and fall risk distribution from a cohort of older adults at risk for falls (Table 1). ${ }^{14} \mathrm{We}$ derived the base-case CHADS and HAS-BLED scores from an atrial fibrillation trial population. ${ }^{15}$ The discrete-time steps (cycles) were each 3 months long, with a lifetime horizon. Perspective of the analysis was from the public health care system third-party payer, the Ontario Ministry of Health and Long-Term Care. We applied discounting at $1.5 \%$ to both costs and utilities based on the current Canadian Agency for Drugs and Technologies in Health guidelines. ${ }^{16}$ We used within-cycle correction to compensate for biases occurring with discrete-time rather than continuous-time health state transitions. ${ }^{17}$ The results were reported in accordance with the Consolidated Health Economic Evaluation Reporting Standards (CHEERS) statement. ${ }^{18}$

A sample structure of the decision tree is shown in Appendix 1, Supplemental Figure S1. Simulated patients started in

\begin{tabular}{|c|c|c|}
\hline Characteristic & \multicolumn{2}{|c|}{ Value } \\
\hline Age, mean $\pm S D$, yr & \multicolumn{2}{|c|}{$78.3 \pm 5.1$} \\
\hline \multirow[t]{2}{*}{ Female sex, \% } & \multicolumn{2}{|c|}{51} \\
\hline & \multicolumn{2}{|c|}{ HAS-BLED† } \\
\hline CHADS* & Low $<3$ & High $\geq 3$ \\
\hline Low $<3$ & 0.58 & 0.19 \\
\hline High $\geq 3$ & 0.12 & 0.11 \\
\hline \multicolumn{3}{|c|}{$\begin{array}{l}\text { Note: } \text { CHADS = congestive heart failure, hypertension, age } \geq 75 \text { yr, diabetes, } \\
\text { stroke; HAS-BLED = hypertension, abnormal renal and liver function, stroke, } \\
\text { bleeding, labile international normalized ratio, elderly (age }>65 \mathrm{yr} \text { ), drugs or } \\
\text { alcohol ( } \geq 8 \text { drinks/wk); SD = standard deviation. } \\
\text { *Stroke risk score. } \\
\text { †Bleeding risk score. }\end{array}$} \\
\hline
\end{tabular}

the "alive" health state and transitioned to the other states when events were encountered (Appendix 1, Supplemental Figure S2):

- Alive: Simulated patients in the alive health state could transition to the bed-bound state if they had a severe bleed or stroke, leading to severe disability with a modified Rankin Scale score of $5 .^{19}$ Patients could also die from 1 of the events in the model or from other reasons based on age-adjusted mortality rates.

- Bed-bound: Patients in the bed-bound state remained in this state until death, but they could still experience a stroke or bleed. To simplify the model, we assumed that those who were bed-bound did not experience further falls. Bed-bound patients could still take antithrombotic medication for atrial fibrillation because, to our knowledge, no studies have been conducted to show a loss of benefit in this population.

- Dead: Patients who died exited the simulation.

We captured stroke, bleed and fall events by means of tracking variables, which were used to calculate costs and utilities. For adults with a major bleed, antithrombotics were discontinued for 3 months in the simulation, which is a conservative duration allowing for minimal bleeding risk. ${ }^{20} \mathrm{We}$ chose the most effective (highest) dosages of each medication for the stroke-prevention analysis. Patients were assumed to be adherent to the study medication, with no discontinuation, but variation in adherence and effectiveness was accounted for in the model because the efficacy estimates were provided as ranges.

\section{Antithrombotic strategies}

The strategies included the following antithrombotic options available on the Canadian market as of April 2020: ASA, less than $150 \mathrm{mg}$ daily; warfarin, titrated to an international normalized ratio of $2-3$; apixaban, $5 \mathrm{mg}$ twice daily; dabigatran, 110 or $150 \mathrm{mg}$ twice daily; rivaroxaban, $20 \mathrm{mg}$ once daily; and edoxaban, 30 or $60 \mathrm{mg}$ once daily. The Canadian Cardiovascular Society guideline recommends that older adults with atrial fibrillation receive antithrombotic 
therapy for stroke prophylaxis; ${ }^{21}$ thus, we did not simulate a "no-treatment" strategy. Since we could not identify any randomized trial data on reduced-dose apixaban $(2.5 \mathrm{mg})$ or rivaroxaban $(15 \mathrm{mg})$, those dosages were excluded from the analysis.

\section{Outcomes}

Health gains were expressed as discounted life years (LYs) and discounted QALYs (to account for both survival and quality of life), and costs were calculated as discounted total lifetime costs. Details of outcome determination are provided in Appendix 1. We compared pairs of strategies by calculating the incremental cost-effectiveness ratio (ICER) as the difference in the grand averages of costs divided by the difference in the grand averages of QALYs. We calculated ICERs by ranking all the strategies by cost, from lowest to highest. We set the willingness-to-pay threshold for this analysis at an ICER of less than \$50 000 per QALY gained based on the commonly accepted threshold range in Canada. ${ }^{22,23}$ Secondary outcomes included life expectancy, cumulative major stroke, cumulative major bleeding, cumulative bed-bound state and length of time off medication.

\section{Model probabilities, cost and utilities}

We conducted a targeted MEDLINE search of articles published in English between 1985 and 2019 to obtain baseline probabilities and utilities for events related to stroke, bleeding and falls (Table 2). We preferentially included articles that reported estimates from randomized trials and large observational cohorts, as well as event probabilities in older adult populations. We derived the baseline mortality rate for each age from Statistics Canada Ontario life tables. ${ }^{40}$ Appropriate distributions were created for each variable for outer-loop sampling. A detailed description of the model variables is available in Appendix 1.

We derived the probability of falls, stroke (major or minor), bleed (major or minor) and death from published trial or cohort estimates (Table 2). The probability of first and subsequent falls was based on the fall cohort of Tinetti and colleagues. ${ }^{14}$ Each fall led to an increased risk of major bleeding, with a hazard ratio derived from an atrial fibrillation clinical trial that captured fall data. ${ }^{24} \mathrm{We}$ derived the efficacy estimates (odds ratios for stroke, bleed and death) for each medication from a network meta-analysis (Table 3), ${ }^{9}$ and derived the odds of bleeding, stroke and death from no treatment compared to warfarin from a 1994 meta-analysis of the original warfarin trials for atrial fibrillation. ${ }^{2}$ We used the notreatment estimate during the period off medication after a major bleed. We defined major bleeding as a bleed accompanied by a decrease in the hemoglobin level of at least $20 \mathrm{~g} / \mathrm{L}$ or requiring transfusion of 2 units or more of packed red blood cells, occurring at a critical site or resulting in death. ${ }^{42}$ All other bleeds were considered minor.

We derived costs related to falls, stroke and bleed from Canadian estimates, ${ }^{34,35}$ and those of clinical events from a study reporting on costs from the Ontario Case Costing Initiative, a provincial database reporting on inpatient events. ${ }^{35}$
We obtained medication costs from the Ontario Drug Benefits Formulary. ${ }^{43}$ Indirect costs of warfarin therapy including blood monitoring and clinic visits were accounted for. ${ }^{41} \mathrm{We}$ adjusted cost data for inflation to 2018 values using the Bank of Canada Consumer Price Index.

We derived utilities from published estimates. All patients entering the cohort began with the utility of having atrial fibrillation. ${ }^{39}$ We factored the utility of stroke or bleed into the existing utility when those events occurred. A minor stroke, minor bleed or fall was associated with a disutility for a defined period of time, but not permanently.

\section{Statistical analysis}

We determined the number of outer- and inner-loop iterations required for the main analysis empirically according to stability of ICER and average cost estimates by running samples of different numbers of outer or inner loops while holding the other constant. The lowest number of outer and inner loops that resulted in stable average values was determined to be 10000 and 5000, respectively.

We performed 1-way deterministic sensitivity analyses for mean age, fall risk and bleed risk. ${ }^{6}$ These variables are most clinically relevant when determining the use of anticoagulants. We plotted the average cost-effectiveness outcome (cost per QALY gained) against a range of parameter estimates.

We evaluated face validity of the model structure and outputs by consulting experts in cardiology (H.C.W.) and geriatric medicine (S.E.S.). The structure of the model is similar to that of a fall and antithrombotic therapy model published in 1999. ${ }^{8}$ Verification was done by 2 programmers who independently examined the modelling steps, checked equations and reviewed TreeAge calculations to ensure accuracy. We tested the external validity of the model by comparing model outputs (cumulative falls, cumulative risk of stroke) to published cohorts. Validation results are presented in Appendix 1.

\section{Ethics approval}

Since this was a modelling study, no ethics approval was needed.

\section{Results}

Apixaban was associated with the greatest number of QALYs gained, at 5.86, and ASA had the lowest effectiveness, at 4.89 QALYs gained (Table 4). Acetylsalicylic acid had the lowest lifetime cost, at $\$ 83834$, and dabigatran, $150 \mathrm{mg}$, had the highest cost, at $\$ 114818$.

Secondary outcomes are shown in Table 5. Both life years and life expectancy were longest with apixaban and shortest with ASA (7.36 v. $6.25 \mathrm{LYs})$. The proportion of patients with major stroke was lowest with dabigatran, $150 \mathrm{mg}$, and highest with ASA (9.8\% v. 26.9\%). Major bleeds occurred most frequently with dabigatran, $150 \mathrm{mg}(42.7 \%)$ and least frequently with ASA (14.2\%). Patients in the model spent an average of 3.45 months without medication with dabigatran, $150 \mathrm{mg}$, versus 1.12 months with ASA. The proportion of patients with severe physical limitation (bed-bound state) due to bleed 


\begin{tabular}{|c|c|c|}
\hline Variable & Estimate (range) & Distribution \\
\hline \multicolumn{3}{|l|}{ Probability } \\
\hline First fall & $0.32(0.27$ to 0.37$)$ & $\beta^{14}$ \\
\hline Subsequent fall & $0.58(0.39$ to 0.97$)$ & $\beta^{14}$ \\
\hline HR bleed after a fall & 1.39 (1.05 to 1.84$)$ & Lognormal $^{24}$ \\
\hline \multicolumn{3}{|l|}{ Any bleed } \\
\hline HAS-BLED score high, annual & $0.166(0.111$ to 0.221$)$ & $\beta^{13}$ \\
\hline HAS-BLED score low, annual & $0.091(0.061$ to 0.121$)$ & $\beta^{13}$ \\
\hline Major bleed given any bleed & $0.31(0.25$ to 0.46$)$ & $\beta^{25}$ \\
\hline Intracranial bleed given major bleed & $0.21(0.14$ to 0.28$)$ & $\beta^{26}$ \\
\hline $\begin{array}{l}\text { Bed-bound after intracranial bleed (modified } \\
\text { Rankin Scale score } \geq 5 \text { ) }\end{array}$ & $0.176(0.117$ to 0.235$)$ & $\beta^{27}$ \\
\hline \multicolumn{3}{|l|}{ Any stroke } \\
\hline High CHADS score & $0.037(0.025$ to 0.049$)$ & Lognormal $^{28}$ \\
\hline Low CHADS score & $0.083(0.055$ to 0.111$)$ & Lognormal $^{28}$ \\
\hline Major stroke given stroke & $0.41(0.20$ to 0.61$)$ & $\beta^{29}$ \\
\hline $\begin{array}{l}\text { Bed-bound after major stroke (modified } \\
\text { Rankin Scale score } \geq 5 \text { ) }\end{array}$ & $0.176(0.117$ to 0.235$)$ & $\beta^{30}$ \\
\hline OR death due to atrial fibrillation & 1.6 (1.2 to 2.2$)$ & Lognormal $^{31}$ \\
\hline HR death after major stroke & 5.29 (3.53 to 7.93$)$ & Lognormal $^{32}$ \\
\hline HR death after major bleed & 3.35 (2.12 to 5.27$)$ & Lognormal $^{32}$ \\
\hline HR death given bed-bound & 3.81 (3.37 to 4.31$)$ & Lognormal $^{33}$ \\
\hline \multicolumn{3}{|l|}{ Cost $^{\star}$} \\
\hline Fall, single event & 7286.01 (5464.51 to 9107.51$)$ & $\gamma^{34}$ \\
\hline Major bleed, initial event & 5358.98 (3572.64 to 7145.28$)$ & $\gamma^{35}$ \\
\hline Major bleed, monthly & 6942.54 (4627.99 to 9255.99$)$ & $\gamma^{35}$ \\
\hline Minor bleed, single event & 84.38 (55.89 to 111.78$)$ & $\gamma^{35}$ \\
\hline Major stroke, initial event & 7227.47 (3613.74 to 14441.79$)$ & $\gamma^{35}$ \\
\hline Major stroke, monthly & 6476.51 (4384.7 to 8768.31$)$ & $\gamma^{35}$ \\
\hline Minor stroke, single event & 3613.74 (500.15 to 7227.47$)$ & $\gamma^{35}$ \\
\hline Bed-bound (long-term care assumed) & 4304.91 (2869.94 to 5739.88$)$ & $\gamma^{36}$ \\
\hline \multicolumn{3}{|l|}{ Utility/disutility } \\
\hline Atrial fibrillation & 0.95 (0.93 to 0.98$)$ & $\beta^{37}$ \\
\hline Fall, per event† & $-0.11(-0.08$ to 0.14$)$ & $\beta^{38}$ \\
\hline Major bleed, long-term & $0.60(0.40$ to 0.80$)$ & $\beta^{39}$ \\
\hline Minor bleed, 1 mo† & $-0.13(-0.08$ to -0.13$)$ & $\beta^{39}$ \\
\hline Major stroke, first year & $0.26(0.20$ to 0.50$)$ & $\beta^{39}$ \\
\hline Major stroke, long-term & 0.71 (0.40 to 0.96$)$ & $\beta^{39}$ \\
\hline Minor stroke, first year† & $-0.25(-0.15$ to -0.25$)$ & $\beta^{39}$ \\
\hline Bed-bound (modified Rankin Scale score $\geq 5$ ) & $0.14(-0.01$ to 0.29$)$ & $\beta^{37}$ \\
\hline \multicolumn{3}{|c|}{$\begin{array}{l}\text { Note: } \text { CHADS }=\text { congestive heart failure, hypertension, age } \geq 75 \mathrm{yr} \text {, diabetes, stroke; HAS-BLED }=\text { hypertension, abnormal renal } \\
\text { and liver function, stroke, bleeding, labile international normalized ratio, elderly (age }>65) \text {, drugs or alcohol }(\geq 8 \text { drinks/wk); HR }= \\
\text { hazard ratio; OR = odds ratio. } \\
\text { *In } 2018 \text { Canadian dollars. } \\
\text { †Disutilities. }\end{array}$} \\
\hline
\end{tabular}




\begin{tabular}{|c|c|c|c|c|}
\hline \multirow[b]{2}{*}{ Medication } & \multicolumn{3}{|c|}{ Event; OR (95\% Cl) } & \multirow{2}{*}{$\begin{array}{l}\text { Cost per } \\
\text { month, } \$^{*}\end{array}$} \\
\hline & Any bleed & Any stroke & Death & \\
\hline Acetylsalicylic acid ${ }^{9}$ & 0.59 (0.45 to 0.77$)$ & 1.88 (1.40 to 2.51$)$ & 1.04 (0.88 to 1.33$)$ & 1.02 \\
\hline Apixaban $^{9}$ & 0.67 (0.60 to 0.75$)$ & $0.79(0.66$ to 0.94$)$ & 0.88 (0.79 to 0.98$)$ & 98.02 \\
\hline Dabigatran, $150 \mathrm{mg}^{9}$ & $1.56(0.50$ to 5.74$)$ & $0.65(0.52$ to 0.81$)$ & $0.88(0.77$ to 1.01$)$ & 100.32 \\
\hline Dabigatran, $110 \mathrm{mg}^{9}$ & $0.80(0.69$ to 0.93$)$ & $0.90(0.74$ to 1.10$)$ & $0.91(0.80$ to 1.04$)$ & 100.32 \\
\hline Edoxaban, $60 \mathrm{mg}^{9}$ & $0.84(0.77$ to 0.90$)$ & $0.86(0.74$ to 1.01$)$ & $0.86(0.82$ to 1.01$)$ & 85.20 \\
\hline Edoxaban, $30 \mathrm{mg}^{9}$ & 0.59 (0.54 to 0.64$)$ & $1.13(0.97$ to 1.32$)$ & $0.86(0.78$ to 0.96$)$ & 85.20 \\
\hline Rivaroxaban $^{9}$ & $1.03(0.95$ to 1.11$)$ & $0.88(0.74$ to 1.03$)$ & 0.83 (0.69 to 1.00$)$ & 86.10 \\
\hline Warfarin & 1.00 & 1.00 & 1.00 & $39.45 \ddagger$ \\
\hline Off medication $\dagger$ & 0.77 (0.34 to 1.20$)$ & 1.47 (1.29 to 1.65$)$ & 3.03 (2.79 to 3.27 ) & - \\
\hline
\end{tabular}

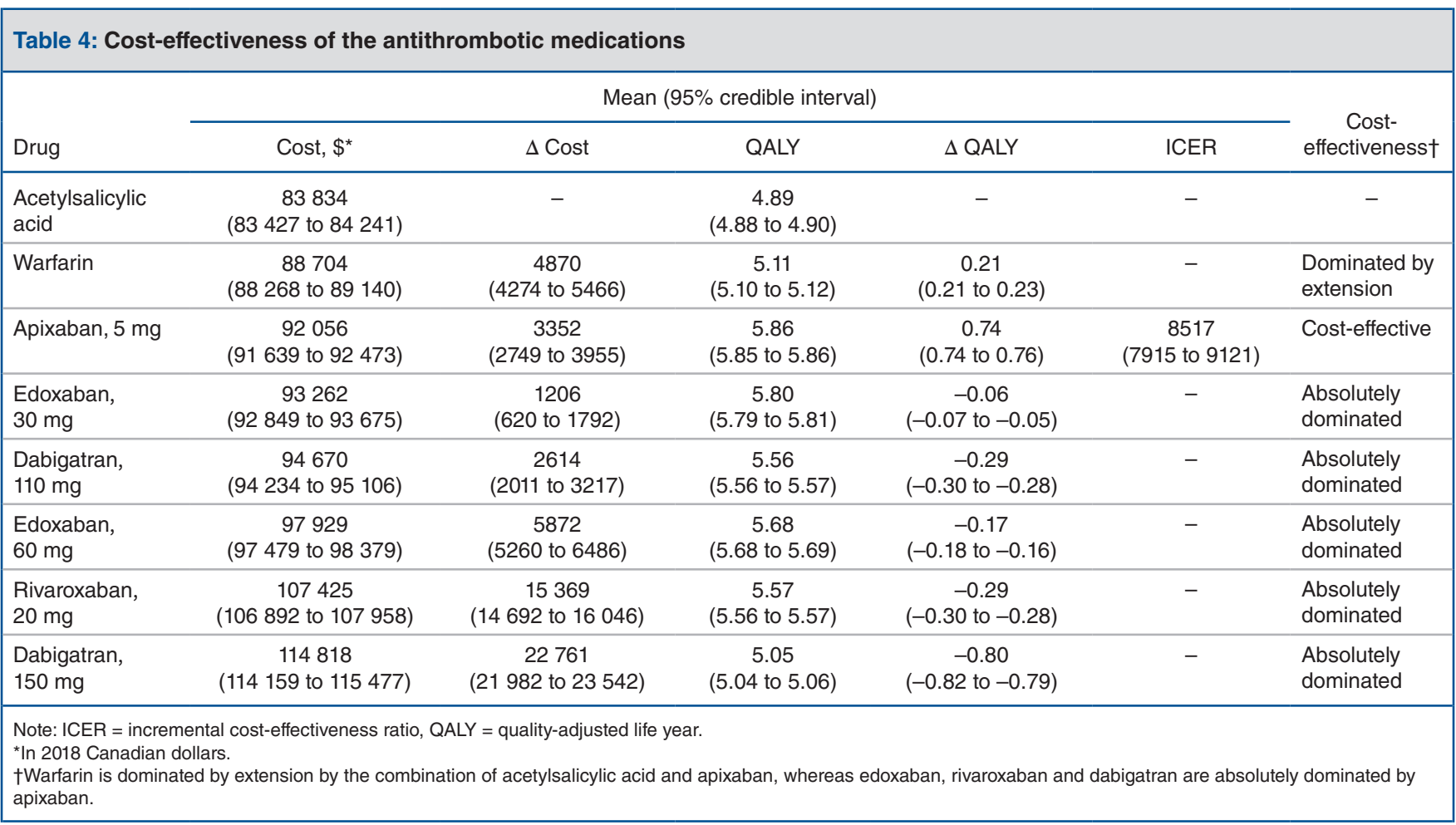

or stroke was similar across the medications, with the lowest proportions among those receiving apixaban $(2.7 \%)$ or dabigatran, $150 \mathrm{mg}(2.3 \%)$.

When listed by increasing lifetime cost, edoxaban (both 30 and $60 \mathrm{mg}$ ), rivaroxaban and dabigatran, $150 \mathrm{mg}$, were absolutely dominated by apixaban, whereas warfarin was dominated by extension by ASA and apixaban (Figure 1). Extended dominance means that the effectiveness of warfarin can be achieved with less cost by a combination policy of ASA and apixaban, wherein a proportion of patients could be given ASA and the rest apixaban. Apixaban was economically attractive relative to ASA, with 0.97 extra QALYs, an increase in lifetime discounted costs of $\$ 8222$ and an ICER of $\$ 8517$ per QALY gained (Table 4).

When we explored variable uncertainty, apixaban was the preferred strategy in $66 \%$ of the outer-loop iterations given a willingness to pay of $\$ 50000$ per QALY gained (Figure 2; Appendix 1, Supplemental Figure S3). There was 


\begin{tabular}{|c|c|c|c|c|c|c|}
\hline Drug & \multicolumn{6}{|c|}{ Mean ( $95 \%$ credible interval) } \\
\hline Warfarin & $\begin{array}{c}6.61 \\
\text { (6.60 to } 6.62)\end{array}$ & $\begin{array}{c}84.7 \\
(84.7 \text { to } 84.7)\end{array}$ & $\begin{array}{c}14.4 \\
(14.4 \text { to } 14.5)\end{array}$ & $\begin{array}{c}25.5 \\
\text { (25.4 to } 25.5)\end{array}$ & $\begin{array}{c}2.04 \\
\text { (2.03 to } 2.04)\end{array}$ & $\begin{array}{c}3.2 \\
\text { (3.2 to } 3.2 \text { ) }\end{array}$ \\
\hline Apixaban, $5 \mathrm{mg}$ & $\begin{array}{c}7.36 \\
\text { (7.35 to } 7.37 \text { ) }\end{array}$ & $\begin{array}{c}85.5 \\
\text { (85.5 to } 85.5)\end{array}$ & $\begin{array}{c}12.9 \\
(12.9 \text { to } 13.1)\end{array}$ & $\begin{array}{c}19.4 \\
(19.4 \text { to } 19.5)\end{array}$ & $\begin{array}{c}1.57 \\
\text { (1.56 to } 1.57)\end{array}$ & $\begin{array}{c}2.7 \\
\text { (2.7 to } 2.7 \text { ) }\end{array}$ \\
\hline Edoxaban, 30 mg & $\begin{array}{c}7.30 \\
\text { (7.29 to } 7.30)\end{array}$ & $\begin{array}{c}85.4 \\
\text { (85.4 to } 85.4)\end{array}$ & $\begin{array}{c}18.4 \\
\text { (18.4 to } 18.5)\end{array}$ & $\begin{array}{c}16.5 \\
(16.5 \text { to } 16.6)\end{array}$ & $\begin{array}{c}1.32 \\
(1.32 \text { to } 1.33)\end{array}$ & $\begin{array}{c}4.0 \\
\text { (4.0 to } 4.0)\end{array}$ \\
\hline Edoxaban, 60 mg & $\begin{array}{c}7.28 \\
\text { (7.28 to } 7.29)\end{array}$ & $\begin{array}{c}85.4 \\
\text { (85.4 to } 85.4)\end{array}$ & $\begin{array}{c}13.8 \\
(13.8 \text { to } 13.9)\end{array}$ & $\begin{array}{c}23.6 \\
\text { (23.6 to } 29.3 \text { ) }\end{array}$ & $\begin{array}{c}1.91 \\
(1.90 \text { to } 1.91)\end{array}$ & $\begin{array}{c}2.9 \\
\text { (2.9 to } 2.9 \text { ) }\end{array}$ \\
\hline Rivaroxaban, 20 mg & $\begin{array}{c}7.30 \\
\text { (7.29 to } 7.31)\end{array}$ & $\begin{array}{c}85.4 \\
(85.4 \text { to } 85.4)\end{array}$ & $\begin{array}{c}14.1 \\
(14.1 \text { to } 14.3)\end{array}$ & $\begin{array}{c}29.2 \\
(29.2 \text { to } 29.3)\end{array}$ & $\begin{array}{c}2.36 \\
\text { (2.35 to } 2.37)\end{array}$ & $\begin{array}{c}3.0 \\
(3.0 \text { to } 3.0)\end{array}$ \\
\hline Dabigatran, 150 mg & $\begin{array}{c}6.91 \\
\text { (6.90 to } 6.92)\end{array}$ & $\begin{array}{c}85.0 \\
(84.9 \text { to } 85.0)\end{array}$ & $\begin{array}{c}9.8 \\
(9.7 \text { to } 9.8)\end{array}$ & $\begin{array}{c}42.7 \\
\text { (42.5 to } 43.0)\end{array}$ & $\begin{array}{c}3.45 \\
\text { (3.43 to } 3.47)\end{array}$ & $\begin{array}{c}2.3 \\
\text { (2.2 to } 2.3)\end{array}$ \\
\hline
\end{tabular}

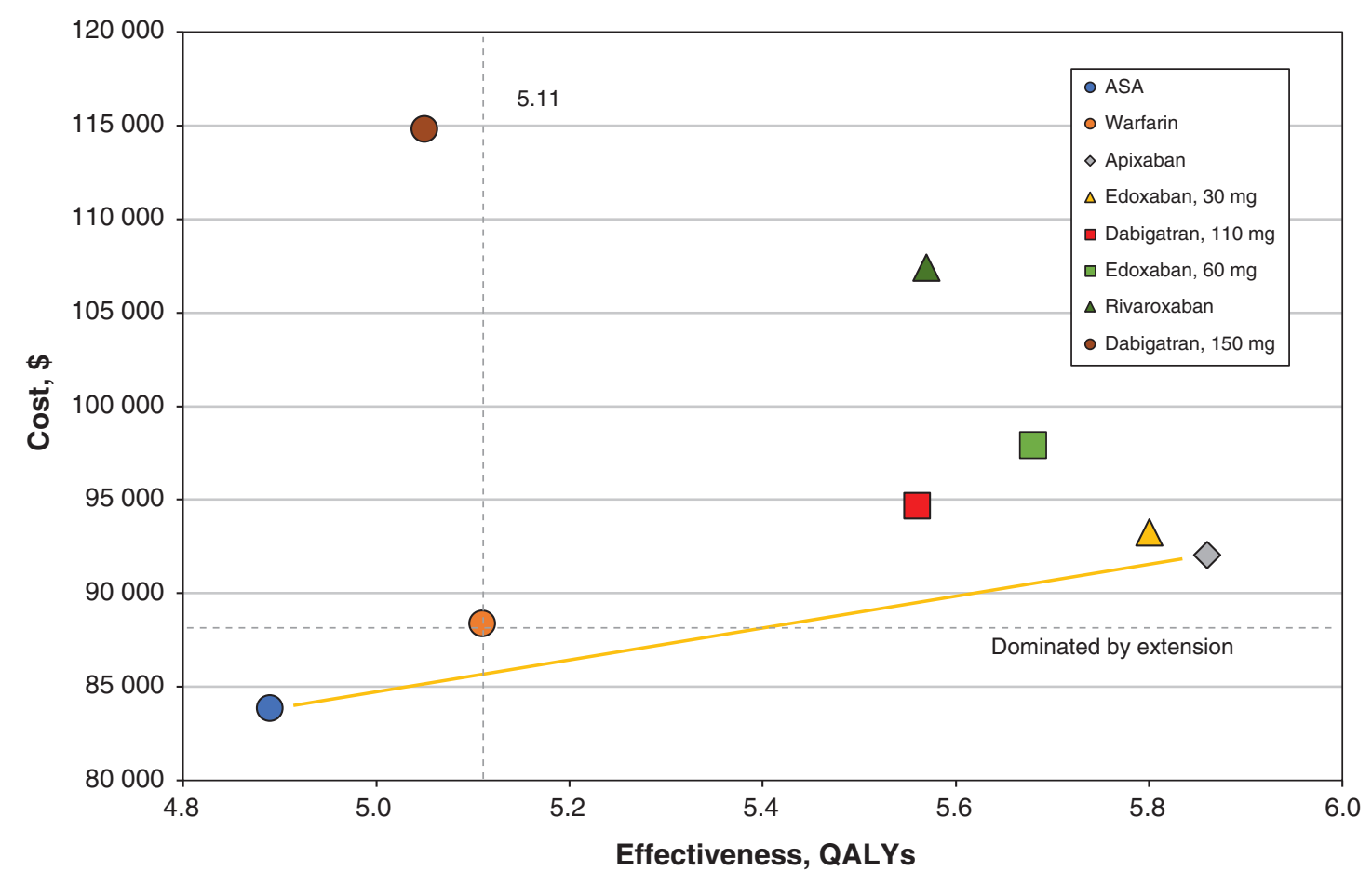

Figure 1: Average cost-effectiveness plane. Medications that were lower in cost and higher in effectiveness were more cost-effective. Warfarin was dominated by extension (beige line) by the combination of apixaban and acetylsalicylic acid (ASA). Note: QALY = quality-adjusted life year. 


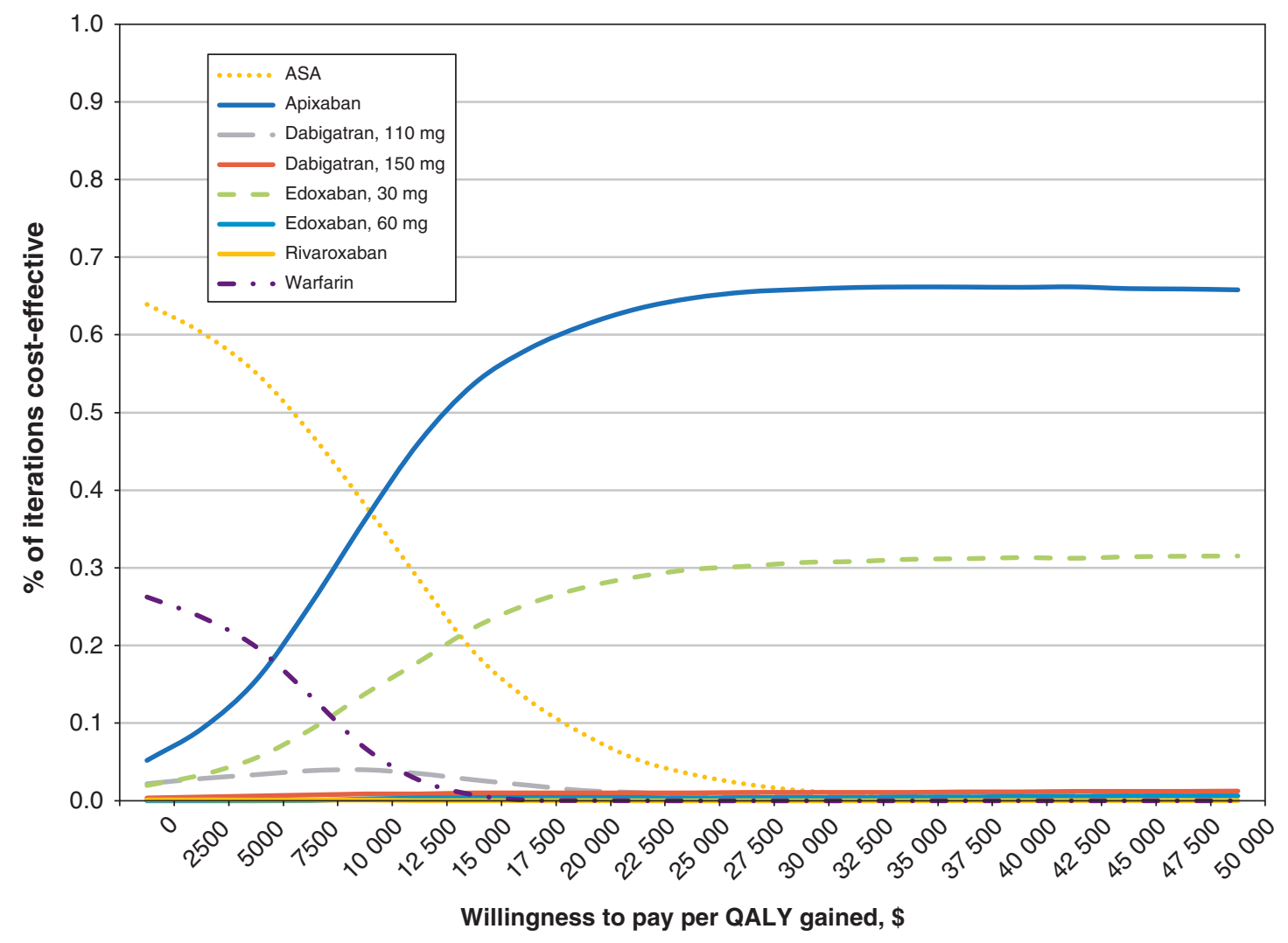

Figure 2: Cost-effectiveness acceptability curve for all antithrombotics. The proportion of model iterations in which the drug was most costeffective reflects residual uncertainty in the model results. Note: ASA = acetylsalicylic acid, QALY = quality-adjusted life year.

moderate uncertainty in the overall results given that edoxaban, $30 \mathrm{mg}$, was most cost-effective in $31 \%$ of the outerloop iterations at a willingness to pay of $\$ 50000$ per QALY gained.

\section{Sensitivity analysis}

In deterministic sensitivity analyses, apixaban had the lowest cost per QALY gained across the full range of values for fall risk and mean age at start (Appendix 1, Supplemental Figure S4). When the baseline probability of clinically important bleeding was increased beyond 0.25 per year (model estimate 0.09), the model favoured ASA over apixaban.

\section{Interpretation}

Our health state transition model showed apixaban to be the preferred strategy from a public payer perspective for stroke prevention in older patients with atrial fibrillation and increased fall risk. The overall reduction in stroke and bleeding events led to a gain in QALYs despite slightly higher lifetime costs of apixaban than of warfarin (\$92056 v. \$88 704). Edoxaban, $30 \mathrm{mg}$, had the lowest bleeding risk of all the direct oral anticoagulants, but it was also least effective in stroke prevention. Sensitivity analyses across ranges of mean age, bleeding risk and fall risk did not show edoxaban to be preferred. Since older adults with falls often have higher stroke and bleeding risk, it is clinically plausible that apixaban is most cost-effective because it best balances stroke prevention while avoiding bleeds.

A previous Canadian cost-effectiveness analysis showed that, with a willingness-to-pay threshold of $\$ 50000$, dabiga$\operatorname{tran}(150 \mathrm{mg})$ was the dominant strategy for the general atrial fibrillation population. ${ }^{10}$ Dabigatran had a lower lifetime cost overall in that study owing to the lower risk of bleeding in a population without fall risk. Although an early decision analysis by Man-Son-Hing and colleagues ${ }^{8}$ did not include costs, our findings are similar to theirs in that anticoagulation was preferred over ASA.

Our analysis builds on prior knowledge that anticoagulation is warranted, but also that apixaban is the most economically attractive choice for stroke prophylaxis in older patients with atrial fibrillation. Although a randomized trial of reduced-dose dabigatran and edoxaban indicated more favourable bleeding profiles compared to their full-dose 
formulations, ${ }^{26}$ our model suggests that apixaban remains the preferred strategy, with the option to reduce the dosage based on the patient's age, weight and renal function. However, there remains uncertainty in the model's results owing to the combination of parameter uncertainty and individual variability. Given this uncertainty, further research directed toward narrowing the confidence intervals around stroke prevention effectiveness and bleeding risk would help to ensure that the most cost-effective medication is provided to older patients with atrial fibrillation.

The most recent study of trends in prescribing oral anticoagulants in Canada, published in 2015, showed a growing trend for apixaban and rivaroxaban prescriptions for any indication. ${ }^{44}$ Future studies should investigate whether low-dose $(2.5 \mathrm{mg})$ apixaban reduces bleeding risk more than the standard dosage $(5 \mathrm{mg})$ in this population. ${ }^{45}$

Strengths of our model include the fact that it simulated a population of older adults at risk for falls with varying stroke and bleeding risks, in the absence of direct clinical trial evidence in this population. The model was fully probabilistic, so reasonable variations in all the model variables were considered simultaneously instead of our performing deterministic sensitivity analysis for a subset of variables 1 at a time. Furthermore, we used efficacy data from a recent systematic review and network meta-analysis that compared all of the pharmacologic treatment strategies available on the Canadian market, including ASA and warfarin. ${ }^{9}$ We included indirect costs of warfarin therapy, including blood investigations for monitoring and clinical visits, as well as Canadian cost estimates for falls, strokes and bleeds. In addition, this was an investigator-initiated study, with no industry funding or influence. Finally, we validated the model externally using large population cohorts.

\section{Limitations}

Our model has several limitations. It was specific to older adults with atrial fibrillation at risk for falls. Simulated patients remained at elevated fall risk throughout the model despite evidence that the risk of falls decreases after 12 months without a subsequent fall. ${ }^{46}$ Patients could fall only once per cycle, and they could no longer fall once they became bed-bound. The results from this model may not be applicable to patients who fall more frequently than once every 3 months. Patients were limited to the use of 1 medication in the model and were assumed to be adherent to the drug. They could not discontinue or transition to another medication with a bleeding event, and medication compliance was not factored into the analysis. We derived the baseline individual characteristics from 2 cohorts because no single cohort had all required falls, age, sex, bleeding and stroke risk parameters. Finally, when more than 1 dosage of a medication was available, we simulated only the most effective dosage (based on stroke reduction). Given these assumptions, our model represents an average set of patients. The model can help guide decisions for policymakers, but direct evidence, if available, should be used to confirm the findings.

\section{Conclusion}

Our model provides guidance to the Ontario Ministry of Health and Long-Term Care as to which antithrombotic medication is ideal for older adults with atrial fibrillation and falls. The findings from this study can guide policies to include cost-effectiveness as a factor when choosing antithrombotic medications for this population.

\section{References}

1. Kamel H, Okin PM, Elkind MSV, et al. Atrial fibrillation and mechanisms of stroke: time for a new model. Stroke 2016;47:895-900.

2. Risk factors for stroke and efficacy of antithrombotic therapy in atrial fibrillation: analysis of pooled data from five randomized controlled trials [published erratum in Arch Intern Med 1994;154:2254]. Arch Intern Med 1994;154:1449-57.

3. Lloyd-Jones DM, Wang TJ, Leip EP, et al. Lifetime risk for development of atrial fibrillation: the Framingham Heart Study. Circulation 2004;110:1042-6.

4. Seshadri S, Beiser A, Kelly-Hayes M, et al. The lifetime risk of stroke: estimates from the Framingham Study. Stroke 2006;37:345-50.

5. An SJ, Kim TJ, Yoon BW. Epidemiology, risk factors, and clinical features of intracerebral hemorrhage: an update. 7 Stroke 2017;19:3-10.

6. Reddy S, Sharma R, Grotts J, et al. Incidence of intracranial hemorrhage and outcomes after ground-level falls in geriatric trauma patients taking preinjury anticoagulants and antiplatelet agents. Am Surg 2014;80:975-8.

7. Sen S, Dahlberg KW. Physician's fear of anticoagulant therapy in nonvalvular atrial fibrillation. Am 7 Med Sci 2014;348:513-21.

8. Man-Son-Hing M, Nichol G, Lau A, et al. Choosing antithrombotic therapy for elderly patients with atrial fibrillation who are at risk for falls. Arch Intern Med 1999;159:677-85.

9. López-López JA, Sterne JAC, Thom HHZ, et al. Oral anticoagulants for prevention of stroke in atrial fibrillation: systematic review, network meta-analysis, and cost effectiveness analysis. BM7 2017;359:j5058.

10. Wells G, Coyle D, Cameron C, et al. Safety, effectiveness, and cost-effectiveness of new oral anticoagulants compared with warfarin in preventing stroke and other cardiovascular events in patients with atrial fibrillation: CADTH therapeutic review. Ottawa: Canadian Agency for Drugs and Technologies in Health; 2012.

11. Owens DK, Whitlock EP, Henderson J, et al.; U.S. Preventive Services Task Force. Use of decision models in the development of evidence-based clinical preventive services recommendations: methods of the U.S. Preventive Services Task Force. Ann Intern Med 2016;165:501-8.

12. Gage BF, Waterman AD, Shannon $W$, et al. Validation of clinical classification schemes for predicting stroke: results from the National Registry of Atrial Fibrillation. FAMA 2001;285:2864-70.

13. Apostolakis S, Lane DA, Guo Y, et al. Performance of the HEMORR 2 HAGES, ATRIA, and HAS-BLED bleeding risk-prediction scores in patients with atrial fibrillation undergoing anticoagulation: the AMADEUS (Evaluating the Use of SR34006 Compared to Warfarin or Acenocoumarol in Patients With Atrial Fibrillation) study. 7 Am Coll Cardiol 2012;60:861-7.

14. Tinetti ME, Speechley M, Ginter SF. Risk factors for falls among elderly persons living in the community. NEngl f Med 1988;319:1701-7.

15. Lopes RD, Al-Khatib SM, Wallentin L, et al. Efficacy and safety of apixaban compared with warfarin according to patient risk of stroke and of bleeding in atrial fibrillation: a secondary analysis of a randomised controlled trial. Lancet 2012;380:1749-58.

16. Guidelines for the economic evaluation of health technologies: Canada. 4th ed. Ottawa: Canadian Agency for Drugs and Technologies in Health: 2017.

17. Elbasha EH, Chhatwal J. Myths and misconceptions of within-cycle correction: a guide for modelers and decision makers. Pharmacoeconomics 2016;34: $13-22$.

18. Husereau D, Drummond M, Petrou S, et al.; CHEERS Task Force. Consolidated Health Economic Evaluation Reporting Standards (CHEERS) statement. BMF 2013;346:f1049.

19. van Swieten JC, Koudstaal PJ, Visser MC, et al. Interobserver agreement for the assessment of handicap in stroke patients. Stroke 1988;19:604-7.

20. Majeed A, Kim YK, Roberts RS, et al. Optimal timing of resumption of warfarin after intracranial hemorrhage. Stroke 2010;41:2860-6.

21. Andrade JG, Verma A, Mitchell LB, et al.; CCS Atrial Fibrillation Guidelines Committee. 2018 focused update of the Canadian Cardiovascular Society guidelines for the management of atrial fibrillation. Can 7 Cardiol 2018;34: 1371-92.

22. Pandey H, Paulden M, McCabe C. Theoretical models of the cost-effectivenes threshold, value assessment, and bealth care system sustainability. Edmonton: Institute of Health Economics; 2018.

23. Laupacis A, Feeny D, Detsky AS, et al. How attractive does a new technology have to be to warrant adoption and utilization? Tentative guidelines for using clinical and economic evaluations. CMAJ 1992;146:473-81.

24. Rao MP, Vinereanu D, Wojdyla DM, et al.; Apixaban for Reduction in Stroke Other Thromboembolic Events in Atrial Fibrillation (ARISTOTLE) 
Investigators. Clinical outcomes and history of fall in patients with atrial fibrillation treated with oral anticoagulation: insights from the ARISTOTLE trial. Am 7 Med 2018;131:269-75.e2.

25. Bahit MC, Lopes RD, Wojdyla DM, et al. Non-major bleeding with apixaban versus warfarin in patients with atrial fibrillation. Heart 2017;103:623-8.

26. Granger CB, Alexander JH, McMurray JJV, et al.; ARISTOTLE Committees and Investigators. Apixaban versus warfarin in patients with atrial fibrillation. $N$ Engl 7 Med 2011;365:981-92.

27. Asuzu D, Nystrom K, Amin H, et al. Modest association between the discharge modified Rankin Scale score and symptomatic intracerebral hemorrhage after intravenous thrombolysis. 7 Stroke Cerebrovasc Dis 2015;24:548-53.

28. Van Staa TP, Setakis E, Di Tanna GL, et al. A comparison of risk stratification schemes for stroke in 79,884 atrial fibrillation patients in general practice. $\mathcal{F}$ Thromb Haemost 2011;9:39-48.

29. Acciarresi M, Paciaroni M, Agnelli G, et al. Prestroke $\mathrm{CHA}_{2} \mathrm{DS}_{2}$-VASc score and severity of acute stroke in patients with atrial fibrillation: findings from RAF Study. 7 Stroke Cerebrovasc Dis 2017;26:1363-8.

30. Olavarría VV, Brunser A, Cabral N, et al. The distribution of the modified Rankin Scale scores change according to eligibility criteria in acute ischemic stroke trials: a consideration for sample size calculations when using ordinal regression analysis. Contemp Clin Trials Commun 2017;5:133-6.

31. Benjamin EJ, Wolf PA, D'Agostino RB, et al. Impact of atrial fibrillation on the risk of death: the Framingham Heart Study. Circulation 1998;98:946-52.

32. De Caterina R, Connolly SJ, Pogue J, et al.; ACTIVE Investigators. Mortality predictors and effects of antithrombotic therapies in atrial fibrillation: insights from ACTIVE-W. Eur Heart 7 2010;31:2133-40.

33. Eriksson M, Norrving B, Terént A, et al. Functional outcome 3 months after stroke predicts long-term survival. Cerebrovasc Dis 2008;25:423-9.

34. The economic burden of injury in Canada. Toronto: SMARTRISK; 2009.

35. Singh SM, Micieli A, Wijeysundera HC. Economic evaluation of percutaneous left atrial appendage occlusion, dabigatran, and warfarin for stroke prevention in patients with nonvalvular atrial fibrillation. Circulation 2013;127:2414-23.

36. About long-term care in Ontario: facts and figures. Toronto: Ontario Long Term Care Association. Available: www.oltca.com/oltca/OLTCA/Public/ LongTermCare/FactsFigures.aspx (accessed 2020 Jan. 9).

37. Ali M, MacIsaac R, Quinn TJ, et al. Dependency and health utilities in stroke: data to inform cost-effectiveness analyses. Eur Stroke 7 2017;2:70-6.

38. Polinder S, Boyé NDA, Mattace-Raso FUS, et al.; IMPROveFALL trial collaborators. Cost-utility of medication withdrawal in older fallers: results from the improving medication prescribing to reduce risk of FALLs (IMPROveFALL) trial. BMC Geriatr 2016;16:179.

39. Tengs TO, Wallace A. One thousand health-related quality-of-life estimates. Med Care 2000;38:583-637.

40. Life tables, Canada, provinces and territories, $1980 / 1982$ to $2016 / 2018$. Ottawa: Statistics Canada; 2020. Available: https://www150.statcan.gc.ca/n1/ pub/84-537-x/84-537-x2019002-eng.htm (accessed 2020 Oct. 30).

41. Schulman S, Anderson DR, Bungard TJ, et al. Direct and indirect costs of management of long-term warfarin therapy in Canada. 7 Thromb Haemost 2010;8:2192-200

42. Schulman S, Kearon C; Subcommittee on Control of Anticoagulation of the Scientific and Standardization Committee of the International Society on
Thrombosis and Haemostasis. Definition of major bleeding in clinical investigations of antihemostatic medicinal products in non-surgical patients. $\mathcal{F}$ Thromb Haemost 2005;3:692-4.

43. Ontario Ministry of Health and Long-Term Care. Drugs funded by Ontario Drug Benefit (ODB) Program: e-formulary. Toronto: Queen's Printer for Ontario; updated 2019 Nov. 29, version 2.8. Available: www.formulary.health. gov.on.ca/formulary/ (accessed 2020 Jan. 9).

44. Weitz JI, Semchuk W, Turpie AGG, et al. Trends in prescribing oral anticoagulants in Canada, 2008-2014. Clin Ther 2015;37:2506-14.e4.

45. Sukumar S, Gulilat M, Linton B, et al. Apixaban concentrations with lower than recommended dosing in older adults with atrial fibrillation. $7 \mathrm{Am}$ Geriatr Soc 2019;67:1902-6.

46. Ganz DA, Bao Y, Shekelle PG, et al. Will my patient fall? FAMA 2007;297:77-86.

Affiliations: Knowledge Translation Program (Wong, Straus), Li Ka Shing Knowledge Institute, St. Michael's Hospital; Institute for Health Policy Management and Evaluation (Wong, Belza, Naimark, Straus, Wijeysundera), Dalla Lana School of Public Health, Division of Nephrology (Naimark), Sunnybrook Health Sciences Centre and Division of Cardiology and Cardiac Surgery (Wijeysundera), Schulich Heart Centre, Sunnybrook Health Sciences Centre, University of Toronto, Toronto, Ont.

Contributors: David Naimark, Sharon Straus and Harindra Wijeysundera supervised the work. Eric Wong, David Naimark, Sharon Straus and Harindra Wijeysundera revised the manuscript critically for important intellectual content. All of the authors conceived and designed the study, analyzed and interpreted the data, drafted the manuscript, approved the final version to be published and agreed to be accountable for all aspects of the work.

Funding: Eric Wong is supported by the Clinician Scientist Training Program at the University of Toronto, a Vanier Canada Graduate Scholarship from the Canadian Institutes of Health Research and the Knowledge Translation Program at St. Michael's Hospital. Sharon Straus is supported by a Tier 1 Canada Research Chair. Harindra Wijeysundera is supported by a Phase 2 Clinician Scientist award from the Heart and Stroke Foundation of Canada, Ontario Office. The Ontario Ministry of Health and Long-Term Care was not involved in this study.

Data sharing: The data are not available to other researchers.

Acknowledgement: The authors thank Dr. Allan Detsky for reviewing a draft of the manuscript in a writing mentorship course.

Supplemental information: For reviewer comments and the original submission of this manuscript, please see www.cmajopen.ca/content/8/4/ E706/suppl/DC1. 